INTERNATIONAL RESEARCH JOURNAL OF PHARMACY

www.irjponline.com

ISSN $2230-8407$

Research Article

\title{
FORMULATION AND EVALUATION OF EXTENDED RELEASE TABLETS OF TRAMADOL HYDROCHLORIDE
}

Chilvalvar Sapnil ${ }^{1 *}$, V. Uma Maheshwara Rao ${ }^{1}$, P. Vishnu ${ }^{1}$, G. Ashok ${ }^{1}$, B. Ajay Kumar ${ }^{2}$

${ }^{1}$ CMR College of Pharmacy, Kandlakoya (V), Hyderabad, Andhra Pradesh, India

${ }^{2}$ Project Coordinator, Richer Pharmaceuticals, Balanagar, Hyderabad, A.P, India

*Corresponding Author Email: sapnil.chilvalvar@gmail.com

Article Received on: 20/08/13 Revised on: 23/09/13 Approved for publication: 17/10/13

DOI: $10.7897 / 2230-8407.041015$

IRJP is an official publication of Moksha Publishing House. Website: www.mokshaph.com

(C) All rights reserved.

\section{ABSTRACT}

The objective of this research work was to develop extended release tablets (Twice in a day) of Tramadol Hydrochloride using different Hydrophilic polymers like HPMC K15M, HPMC K4M, Metalose 60SH50, Carbopol 971P, Sodium alginate, Xanthan gum by direct compression method. Various amounts of polymers was used in the twenty four proposed formulations ( F1 to F24) for the study of release rate retardant effect at $10 \%, 15 \%, 20 \%, 25 \%$ of total weight of tablet matrix respectively. Then the tablets were evaluated in terms of their physical parameters (weight variation, hardness, friability and thickness), drug content and in-vitro release studies. All the formulations showed compliance with pharmacopoeial standards. The in-vitro dissolution study were conducted using USP dissolution apparatus type-II (paddle method) in $900 \mathrm{ml} 0.1 \mathrm{~N} \mathrm{HCl}$ for first $2 \mathrm{~h}$ and remaining $10 \mathrm{~h}$ performed in $6.8 \mathrm{pH}$ phosphate buffer at $100 \mathrm{rpm}$ for a total period of $12 \mathrm{~h}$. Based on the dissolution data comparison with innovator product, formulation F14 was found as the best formulation. The drug release of formulation F14 followed First Order kinetic model and the mechanism was found to be non-Fickian/anomalous according to Korsmeyer-Peppas equation.

Keywords: Tramadol Hydrochloride, Direct Compression, Hydroxy propyl methyl cellulose, Carbopol 971P, Extended Release.

\section{INTRODUCTION}

Extended release formulations make the drug available over extended time period after oral administration. The extended release product will optimize therapeutic effect and safety of a drug at the same time improving the patient convenience and compliance. ${ }^{1}$ Tramadol is used in the treatment of osteoarthritis when non-steroidal anti-inflammatory drug (NSAIDS), acetaminophen, or cox-2 inhibitors alone produce inadequate pain relief. After oral administration, Tramadol is rapidly and almost completely absorbed. Sustained release tablets reach to peak concentration after $5 \mathrm{~h}$ and have a bioavailability of $87 \%$ - $95 \%$. The mean elimination halflife is approximately 6 to $8 \mathrm{~h}$ and requires dosing every $6 \mathrm{~h}$ in order to maintain optimal relief of chronic pain. Consequently once or twice daily extended release tablets have been formulated. Long term treatment with extended release Tramadol tablets once or twice daily is generally safe in patients with osteoarthritis or refractory low back pain and is well tolerated. It has the potential to provide patients increased control over the management of their pain, fewer interruptions in sleep and improved compliance. And minimize drug accumulation with chronic dosing.,

\section{MATERIALS AND METHODS \\ Materials}

Tramadol Hydrochloride was obtained as a gift sample from Aurabindo Pharma, Hyderabad, India. HPMC K4M, HPMC K15M, Carbopol 971P, Xanthan gum, Metolose 60SH50, Sodium alginate, D Extended release formulations make the drug available over extended time period after oral administration. The extended release product will optimize therapeutic effect and safety of a drug at the same time improving the patient convenience and compliance. By incorporating the dose for $24 \mathrm{~h}$ into one tablet/capsule from which the drug is released slowly. This formulation helps to avoid the side effects associated with low and high concentrations. The ideal drug delivery system should show a constant zero-order relei calcium phosphate, Magnesium stearate, Aerosil, obtained from Richer Pharmaceuticals, Hyderabad, India.

\section{Methods}

\section{Drug Excipient Compatibility Studies}

Compatibility study was carried for pure Tramadol Hydrochloride and combination of Tramadol Hydrochloride with excipients. Fourier transfer infra red (FTIR) spectroscopic (shimadzu, Japan) studies were carried out by approximately diluting the sample with dried potassium bromide (1:100) and acquiring infrared (IR) spectrum in the range of 400 to $4000 \mathrm{~cm}^{-1}$.

Formulation of Extended release matrix tablets of Tramadol Hydrochloride by direct compression method Various formulation batches of Tramadol Hydrochloride Extended release tablets were prepared using different polymers at $10 \%, 15 \%, 20 \%, 25 \%$ Concentration of total weight of tablet matrix respectively. All ingredients except magnesium stearate were blended in glass mortar uniformly. Then pass the mixture through sieve $\neq 60$. Add magnesium stearate to the above mixture and pass through sieve $\neq 60$ and mix for 10-15 minutes; finally compressed in concave shaped circular punches $8.5 \mathrm{~mm}$ (Cadmach 16 station).

\section{Evaluation Parameters}

Evaluation of powder blend

Angle of repose

Static angle of repose was determined according to the fixed funnel method; where by accurately weighed powder (3 g) were carefully poured through the funnel with its tip at $2 \mathrm{~cm}$ height $(\mathrm{H})$, until the apex of the conical heap so formed just reached the tip of the funnel ${ }^{4}$. The mean diameter $2 \mathrm{R}$ of the base for the powder cone was measured and the angle of repose $(\Theta)$ was calculated using the following equation.

$$
\operatorname{Tan}(\Theta)=H / R
$$


Bulk density and tapped density

Both poured bulk and tapped bulk densities were determined, where by a quantity ( $3 \mathrm{~g}$ ) of powder blend from each formula, previously lightly shaken to break any agglomerates formed, was introduced into a $10 \mathrm{ml}$ measuring cylinder. After the initial volume was observed, the cylinder was allowed to fall under its own weight onto a hard surface from the height of $2.5 \mathrm{~cm}$ at 2 -second intervals. The tapping was continued until no further change in the volume was noted.

\section{Carr's Compressibility Index and Hausner's ratio}

The compressibility of the powder was determined by carr's compressibility index (CI). The Hausner's ratio (HR) is number that is correlated to the flow ability of powder.

$\mathrm{CI}=((\mathrm{TD}-\mathrm{BD}) / \mathrm{TD}) * 100$

where $\mathrm{TD}=$ tapped density and $\mathrm{BD}=$ bulk density.

\section{$\mathrm{HR}=(100 / 100-\mathrm{CI})$}

\section{Evaluation of Tablets}

The prepared extended release tablets were evaluated for hardness, thickness, friability, weight variation test and drug content. Hardness of tablets was tested using Monsanto hardness tester (Serve well, Bangalore, India). Friability of the tablets was determined in a Roche Friabilator (Electrolab, Mumbai, India). The thickness of tablets was measured by vernier calipers. Weight variation test was performed according to official method. Drug content for Tramadol Hydrochloride was carried out by measuring the absorbance of samples at $273 \mathrm{~nm}$ using Lab India UV-2400PC spectrophotometer Mumbai, India and comparing the content from a calibration curve of Tramadol Hydrochloride. ${ }^{5,6}$

Table 1: Composition of the Formulations (per each tablet in mg)

\begin{tabular}{|c|c|c|c|c|c|c|c|c|c|c|c|}
\hline $\begin{array}{c}\begin{array}{c}\text { Formulation } \\
\text { code }\end{array} \\
\end{array}$ & Drug & DCP & $\begin{array}{c}\text { HPMC } \\
\text { К4M }\end{array}$ & $\begin{array}{c}\text { HPMC } \\
\text { K15M } \\
\end{array}$ & $\begin{array}{c}\text { Metolose } \\
60 \mathrm{SH50} \\
\end{array}$ & $\begin{array}{c}\text { Carbopo } \\
1971 \mathrm{P} \\
\end{array}$ & $\begin{array}{c}\text { Xanthan } \\
\text { gum }\end{array}$ & $\begin{array}{c}\text { Sodium } \\
\text { alginate }\end{array}$ & Aerosil & $\begin{array}{c}\text { Mag. } \\
\text { stearate }\end{array}$ & $\begin{array}{c}\text { Total } \\
(\mathrm{mg} / \mathrm{tab})\end{array}$ \\
\hline F1 & 100 & 164 & 30 & - & - & - & - & - & 3 & 3 & 300 \\
\hline F2 & 100 & 149 & 45 & - & - & - & - & - & 3 & 3 & 300 \\
\hline F3 & 100 & 134 & 60 & - & - & - & - & - & 3 & 3 & 300 \\
\hline F4 & 100 & 119 & 75 & - & - & - & - & - & 3 & 3 & 300 \\
\hline F5 & 100 & 164 & - & 30 & - & - & - & - & 3 & 3 & 300 \\
\hline F6 & 100 & 149 & - & 45 & - & - & - & - & 3 & 3 & 300 \\
\hline F7 & 100 & 134 & - & 60 & - & - & - & - & 3 & 3 & 300 \\
\hline F8 & 100 & 119 & - & 75 & - & - & - & - & 3 & 3 & 300 \\
\hline F9 & 100 & 164 & - & - & 30 & - & - & - & 3 & 3 & 300 \\
\hline F10 & 100 & 149 & - & - & 45 & - & - & - & 3 & 3 & 300 \\
\hline F11 & 100 & 134 & - & - & 60 & - & - & - & 3 & 3 & 300 \\
\hline F12 & 100 & 119 & - & - & 75 & - & - & - & 3 & 3 & 300 \\
\hline F13 & 100 & 164 & - & - & - & 30 & - & - & 3 & 3 & 300 \\
\hline F14 & 100 & 149 & - & - & - & 45 & - & - & 3 & 3 & 300 \\
\hline F15 & 100 & 134 & - & - & - & 60 & - & - & 3 & 3 & 300 \\
\hline F16 & 100 & 119 & - & - & - & 75 & - & - & 3 & 3 & 300 \\
\hline F17 & 100 & 164 & - & - & - & - & 30 & - & 3 & 3 & 300 \\
\hline F18 & 100 & 149 & - & - & - & - & 45 & - & 3 & 3 & 300 \\
\hline F19 & 100 & 134 & - & - & - & - & 60 & - & 3 & 3 & 300 \\
\hline F20 & 100 & 119 & - & - & - & - & 75 & - & 3 & 3 & 300 \\
\hline F21 & 100 & 164 & - & - & - & - & - & 30 & 3 & 3 & 300 \\
\hline F22 & 100 & 149 & - & - & - & - & - & 45 & 3 & 3 & 300 \\
\hline F23 & 100 & 134 & - & - & - & - & - & 60 & 3 & 3 & 300 \\
\hline F24 & 100 & 119 & - & - & - & - & - & 75 & 3 & 3 & 300 \\
\hline
\end{tabular}

Table 2: Pre Compression parameters of Tablets of Batches F1 - F24

\begin{tabular}{|c|c|c|c|c|c|}
\hline Formulation code & Angle of Repose & Bulk Density & Tapped Density & Carr's Index & Hausner's Ratio \\
\hline F1 & $33.54 \pm 1.07$ & $0.59 \pm 0.34$ & $0.69 \pm 0.30$ & $14.49 \pm 0.43$ & $1.16 \pm 0.35$ \\
\hline $\mathrm{F} 2$ & $33.35 \pm 1.01$ & $0.63 \pm 0.25$ & $0.71 \pm 0.28$ & $12.50 \pm 0.27$ & $1.14 \pm 0.54$ \\
\hline F3 & $28.65 \pm 0.86$ & $0.64 \pm 0.45$ & $0.76 \pm 0.19$ & $15.0 \pm 0.18$ & $1.18 \pm 0.2$ \\
\hline $\mathrm{F} 4$ & $27.3 \pm 0.89$ & $0.67 \pm 0.27$ & $0.74 \pm 0.54$ & $9.45 \pm 0.12$ & $1.10 \pm 0.34$ \\
\hline F5 & $32.13 \pm 0.94$ & $0.63 \pm 0.51$ & $0.73 \pm 0.24$ & $13.15 \pm 0.34$ & $1.15 \pm 0.28$ \\
\hline F6 & $33.52 \pm 0.89$ & $0.64 \pm 0.12$ & $0.75 \pm 0.17$ & $14.66 \pm 0.32$ & $1.17 \pm 0.62$ \\
\hline F7 & $31.24 \pm 0.99$ & $0.61 \pm 0.22$ & $0.68 \pm 0.53$ & $10.29 \pm 0.43$ & $1.11 \pm 0.13$ \\
\hline F8 & $33.49 \pm 0.98$ & $0.69 \pm 0.46$ & $0.76 \pm 0.82$ & $9.20 \pm 0.33$ & $1.10 \pm 0.42$ \\
\hline F9 & $32.4 \pm 0.64$ & $0.60 \pm 0.16$ & $0.69 \pm 0.24$ & $13.04 \pm 0.54$ & $1.15 \pm 0.29$ \\
\hline F10 & $33.13 \pm 1.05$ & $0.61 \pm 0.37$ & $0.70 \pm 0.43$ & $12.85 \pm 0.39$ & $1.14 \pm 0.72$ \\
\hline F11 & $32.23 \pm 0.93$ & $0.64 \pm 0.25$ & $0.73 \pm 0.23$ & $12.32 \pm 0.53$ & $1.14 \pm 0.22$ \\
\hline F12 & $31.39 \pm 1.14$ & $0.64 \pm 0.38$ & $0.72 \pm 0.65$ & $11.11 \pm 0.33$ & $1.12 \pm 0.38$ \\
\hline F13 & $30.24 \pm 0.69$ & $0.61 \pm 0.31$ & $0.68 \pm 0.38$ & $10.29 \pm 0.21$ & $1.11 \pm 0.19$ \\
\hline F14 & $32.49 \pm 0.98$ & $0.69 \pm 0.28$ & $0.76 \pm 0.27$ & $9.2 \pm 0.26$ & $1.10 \pm 0.21$ \\
\hline F15 & $31.4 \pm 0.54$ & $0.67 \pm 0.46$ & $0.74 \pm 0.46$ & $9.45 \pm 0.43$ & $1.10 \pm 0.26$ \\
\hline F16 & $32.13 \pm 1.25$ & $0.64 \pm 0.38$ & $0.73 \pm 0.63$ & $12.32 \pm 0.56$ & $1.14 \pm 0.32$ \\
\hline F17 & $31.23 \pm 0.63$ & $0.67 \pm 0.48$ & $0.74 \pm 0.28$ & $9.45 \pm 0.21$ & $1.10 \pm 0.18$ \\
\hline F18 & $32.39 \pm 1.14$ & $0.63 \pm 0.11$ & $0.71 \pm 0.18$ & $11.26 \pm 0.51$ & $1.12 \pm 0.23$ \\
\hline F19 & $31.12 \pm 0.29$ & $0.64 \pm 0.23$ & $0.73 \pm 0.45$ & $12.32 \pm 0.32$ & $1.14 \pm 0.24$ \\
\hline F20 & $30.42 \pm 0.28$ & $0.61 \pm 0.41$ & $0.67 \pm 0.54$ & $8.95 \pm 0.38$ & $1.09 \pm 0.32$ \\
\hline F21 & $29.3 \pm 0.14$ & $0.67 \pm 0.57$ & $0.75 \pm 0.73$ & $13.33 \pm 0.29$ & $1.11 \pm 0.41$ \\
\hline F22 & $31.23 \pm 0.45$ & $0.65 \pm 0.31$ & $0.75 \pm 0.78$ & $13.33 \pm 0.83$ & $1.15 \pm 0.26$ \\
\hline F23 & $30.13 \pm 0.33$ & $0.67 \pm 0.24$ & $0.74 \pm 0.34$ & $9.45 \pm 0.91$ & $1.10 \pm 0.39$ \\
\hline F24 & $31.59 \pm 1.24$ & $0.58 \pm 0.18$ & $0.68 \pm 0.26$ & $14.70 \pm 0.24$ & $1.17 \pm 0.52$ \\
\hline
\end{tabular}


Table 3: Post Compression parameters of Tablets of Batches F1 - F24

\begin{tabular}{|c|c|c|c|c|c|}
\hline Formulation code & Weight variation (mg) & Thickness (mm) & Hardness (kp) & Friability (\%) & Drug content (\%) \\
\hline $\mathrm{F} 1$ & $300 \pm 1.09$ & $4.42 \pm 0.3$ & $5-7$ & $0.16 \pm 0.03$ & $99.22 \pm 0.49$ \\
\hline $\mathrm{F} 2$ & $299 \pm 0.94$ & $4.41 \pm 0.5$ & $5-7$ & $0.13 \pm 0.02$ & $97.40 \pm 0.62$ \\
\hline F3 & $301 \pm 0.59$ & $4.38 \pm 0.6$ & $5-7$ & $0.16 \pm 0.01$ & $98.98 \pm 1.06$ \\
\hline F4 & $300 \pm 1.01$ & $4.43 \pm 0.4$ & $5-7$ & $0.31 \pm 0.02$ & $99.8 \pm 0.54$ \\
\hline F5 & $300 \pm 1.36$ & $4.44 \pm 0.4$ & $5-7$ & $0.11 \pm 0.01$ & $100.18 \pm 0.54$ \\
\hline F6 & $301 \pm 1.57$ & $4.41 \pm 0.5$ & $5-7$ & $0.22 \pm 0.02$ & $97.68 \pm 0.16$ \\
\hline F7 & $300 \pm 0.49$ & $4.42 \pm 0.8$ & $5-7$ & $0.14 \pm 0.05$ & $98.77 \pm 0.95$ \\
\hline F8 & $300 \pm 1.46$ & $4.40 \pm 0.9$ & $5-7$ & $0.12 \pm 0.03$ & $99.56 \pm 1.49$ \\
\hline F9 & $300 \pm 0.95$ & $4.39 \pm 0.9$ & $5-7$ & $0.19 \pm 0.08$ & $100.37 \pm 1.21$ \\
\hline F10 & $299 \pm 1.65$ & $4.42 \pm 0.3$ & $5-7$ & $0.25 \pm 0.02$ & $99.86 \pm 0.39$ \\
\hline F11 & $300 \pm 0.43$ & $4.44 \pm 0.2$ & $5-7$ & $0.12 \pm 0.02$ & $99.53 \pm 1.09$ \\
\hline F12 & $300 \pm 1.03$ & $4.45 \pm 0.8$ & $5-7$ & $0.28 \pm 0.01$ & $98.73 \pm 0.98$ \\
\hline F13 & $300 \pm 0.76$ & $4.46 \pm 0.6$ & $5-7$ & $0.25 \pm 0.03$ & $99.69 \pm 1.07$ \\
\hline F14 & $300 \pm 0.52$ & $4.43 \pm 0.6$ & $5-7$ & $0.17 \pm 0.01$ & $97.98 \pm 1.65$ \\
\hline F15 & $300 \pm 0.40$ & $4.44 \pm 0.3$ & $5-7$ & $0.2 \pm 0.01$ & $100.2 \pm 1.2$ \\
\hline F16 & $300 \pm 0.7$ & $4.42 \pm 0.5$ & $5-7$ & $0.19 \pm 0.005$ & $98.27 \pm 1.22$ \\
\hline F17 & $300 \pm 0.23$ & $4.43 \pm 0.8$ & $5-7$ & $0.18 \pm 0.015$ & $99.29 \pm 0.56$ \\
\hline F18 & $301 \pm 0.65$ & $4.48 \pm 0.7$ & $5-7$ & $0.18 \pm 0.04$ & $99.43 \pm 0.54$ \\
\hline F19 & $300 \pm 0.37$ & $4.46 \pm 0.5$ & $5-7$ & $0.22 \pm 0.01$ & $99.21 \pm 1.23$ \\
\hline $\mathrm{F} 20$ & $298 \pm 1.45$ & $4.42 \pm 0.2$ & $5-7$ & $0.43 \pm 0.02$ & $98.34 \pm 1.32$ \\
\hline F21 & $299 \pm 0.43$ & $4.48 \pm 0.4$ & $5-7$ & $0.20 \pm 0.02$ & $100.28 \pm 0.76$ \\
\hline F22 & $300 \pm 0.61$ & $4.39 \pm 0.4$ & $5-7$ & $0.38 \pm 0.03$ & $99.67 \pm 0.48$ \\
\hline F23 & $299 \pm 0.34$ & $4.45 \pm 0.7$ & $5-7$ & $0.12 \pm 0.01$ & $99.87 \pm 1.27$ \\
\hline F24 & $300 \pm 0.57$ & $4.43 \pm 0.4$ & $5-7$ & $0.24 \pm 0.03$ & $99.34 \pm 01.43$ \\
\hline
\end{tabular}

*All values are expressed as mean $\pm \mathrm{SD}, \mathrm{n}=3$

Table 4: \% Cumulative drug release of formulations F1-F24

\begin{tabular}{|c|c|c|c|c|c|c|c|}
\hline \multirow{2}{*}{$\begin{array}{c}\text { Formulation } \\
\text { Code }\end{array}$} & \multicolumn{7}{|c|}{$\%$ Drug release in hours } \\
\hline & 1 & 2 & 4 & 6 & 8 & 10 & 12 \\
\hline F1 & $29.12 \pm 0.6$ & $43.36 \pm 0.4$ & $60.21 \pm 0.5$ & $79.86 \pm 0.8$ & $98.14 \pm 0.4$ & & \\
\hline F2 & $28.24 \pm 0.8$ & $40.54 \pm 0.5$ & $59.32 \pm 0.5$ & $75.23 \pm 0.5$ & $89.65 \pm 0.6$ & $100.35 \pm 0.2$ & \\
\hline F3 & $26.39 \pm 0.2$ & $34.71 \pm 0.4$ & $52.64 \pm 0.9$ & $66.22 \pm 0.5$ & $83.12 \pm 0.5$ & $98.26 \pm 0.2$ & \\
\hline $\mathrm{F} 4$ & $22.21 \pm 0.5$ & $32.89 \pm 0.6$ & $46.44 \pm 0.5$ & $59.56 \pm 0.4$ & $69.36 \pm 0.2$ & $83.65 \pm 0.6$ & $100.23 \pm 0.2$ \\
\hline F5 & $29.32 \pm 0.6$ & $43.26 \pm 0.4$ & $59.49 \pm 0.5$ & $78.85 \pm 0.8$ & $97.24 \pm 0.4$ & & \\
\hline F6 & $25.24 \pm 0.8$ & $39.54 \pm 0.5$ & $57.32 \pm 0.5$ & $74.23 \pm 0.5$ & $88.65 \pm 0.6$ & $99.35 \pm 0.2$ & \\
\hline F7 & $24.49 \pm 0.2$ & $33.62 \pm 0.4$ & $48.56 \pm 0.9$ & $66.34 \pm 0.5$ & $78.16 \pm 0.5$ & $90.28 \pm 0.2$ & $100.85 \pm 0.4$ \\
\hline F8 & $20.32 \pm 0.5$ & $27.24 \pm 0.6$ & $42.3 \pm 0.5$ & $57.23 \pm 0.4$ & $66.67 \pm 0.2$ & $79.35 \pm 0.6$ & $97.76 \pm 0.2$ \\
\hline F9 & $35.12 \pm 0.6$ & $60.36 \pm 0.4$ & $89.21 \pm 0.5$ & $101.86 \pm 0.8$ & & & \\
\hline F10 & $34.25 \pm 0.24$ & $58.64 \pm 0.46$ & $86.26 \pm 0.61$ & $98.56 \pm 0.17$ & & & \\
\hline F11 & $32.44 \pm 0.48$ & $54.87 \pm 0.56$ & $74.74 \pm 1.20$ & $85.22 \pm 0.51$ & $91.31 \pm 0.65$ & $98.42 \pm 0.23$ & \\
\hline F12 & $30.21 \pm 0.32$ & $49.34 \pm 0.12$ & $60.86 \pm 1.1$ & $75.53 \pm 0.7$ & $87.22 \pm 0.4$ & $95.61 \pm 0.2$ & $100.01 \pm 0.9$ \\
\hline F13 & $26.12 \pm 0.6$ & $40.36 \pm 0.4$ & $55.21 \pm 0.5$ & $69.86 \pm 0.8$ & $83.14 \pm 0.4$ & $96.32 \pm 0.6$ & $101.21 \pm 1.3$ \\
\hline F14 & $19.24 \pm 0.8$ & $28.2 \pm 0.5$ & $43.2 \pm 0.5$ & $54.32 \pm 0.5$ & $67.8 \pm 0.6$ & $78.98 \pm 0.2$ & $99.2 \pm 0.4$ \\
\hline F15 & $17.39 \pm 0.2$ & $25.71 \pm 0.4$ & $34.64 \pm 0.9$ & $39.22 \pm 0.5$ & $46.12 \pm 0.5$ & $58.26 \pm 0.2$ & $70.56 \pm 0.6$ \\
\hline F16 & $15.24 \pm 0.5$ & $22.37 \pm 0.6$ & $29.21 \pm 0.5$ & $33.43 \pm 0.4$ & $39.23 \pm 0.2$ & $44.98 \pm 0.6$ & $48.21 \pm 0.2$ \\
\hline F17 & $27.11 \pm 0.6$ & $41.36 \pm 0.4$ & $55.32 \pm 0.5$ & $69.75 \pm 0.8$ & $82.15 \pm 0.4$ & $97.28 \pm 0.6$ & \\
\hline F18 & $25.25 \pm 0.24$ & $38.64 \pm 0.46$ & $49.26 \pm 0.61$ & $60.56 \pm 0.17$ & $78.85 \pm 0.43$ & $88.34 \pm 0.39$ & $100.66 \pm 1.12$ \\
\hline F19 & $22.44 \pm 0.48$ & $30.87 \pm 0.56$ & $41.74 \pm 1.20$ & $50.22 \pm 0.51$ & $59.31 \pm 0.65$ & $67.42 \pm 0.23$ & $76.29 \pm 0.64$ \\
\hline F20 & $14.21 \pm 0.32$ & $21.34 \pm 0.12$ & $30.86 \pm 1.1$ & $39.53 \pm 0.7$ & $46.22 \pm 0.4$ & $57.61 \pm 0.2$ & $65.01 \pm 0.9$ \\
\hline F21 & $45.12 \pm 0.6$ & $70.36 \pm 0.4$ & $92.21 \pm 0.5$ & $101.16 \pm 1.8$ & & & \\
\hline $\mathrm{F} 22$ & $34.24 \pm 0.24$ & $48.52 \pm 0.46$ & $69.29 \pm 0.61$ & $80.44 \pm 0.17$ & $100.72 \pm 0.43$ & & \\
\hline $\mathrm{F} 23$ & $31.32 \pm 0.48$ & $48.84 \pm 0.56$ & $64.72 \pm 1.20$ & $78.53 \pm 0.51$ & $94.31 \pm 0.65$ & $100.42 \pm 0.2$ & \\
\hline F24 & $22.32 \pm 0.32$ & $34.56 \pm 0.12$ & $52.83 \pm 1.1$ & $66.24 \pm 0.7$ & $83.31 \pm 0.4$ & $97.56 \pm 0.2$ & \\
\hline MP & $18.65 \pm 0.36$ & $26.28 \pm 0.43$ & $39.26 \pm 0.28$ & $49.17 \pm 0.65$ & $62.21 \pm 0.37$ & $74.54 \pm 0.81$ & $96.43 \pm 0.31$ \\
\hline
\end{tabular}

*All values are expressed as mean $\pm \mathrm{SD}, \mathrm{n}=3$ 


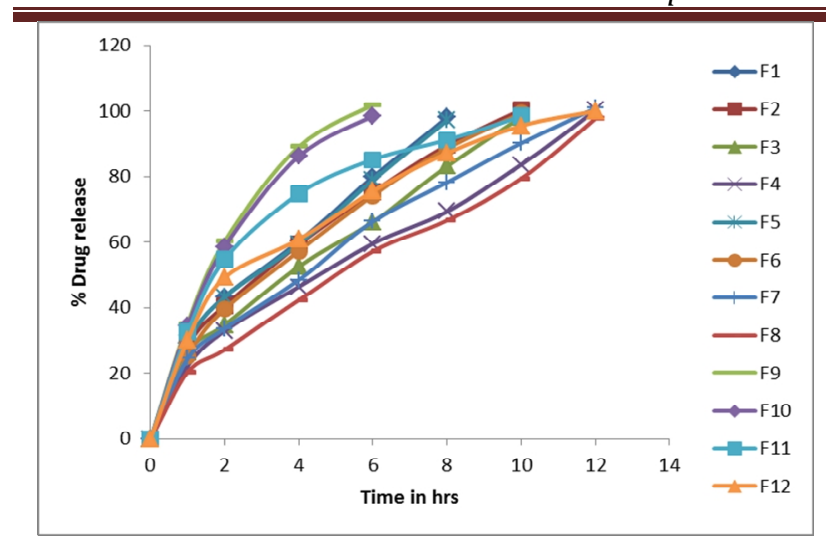

Figure 1: In-vitro Dissolution Profile For Batches F1 - F12

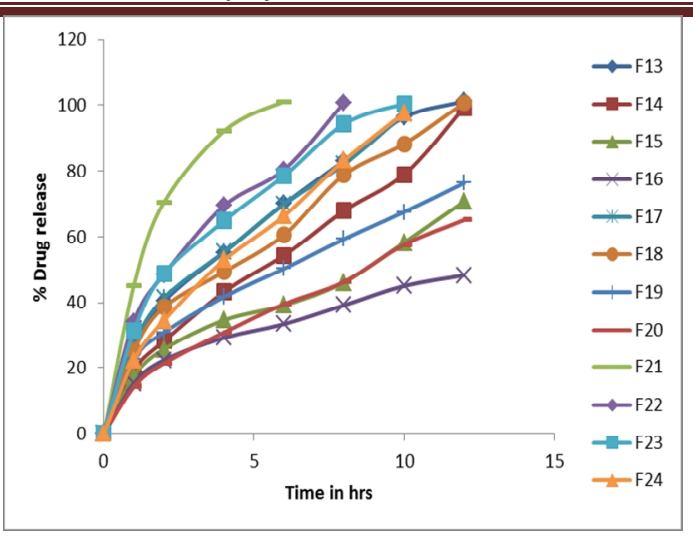

Figure 2: In-vitro Dissolution Profile For Batches F13 - F24

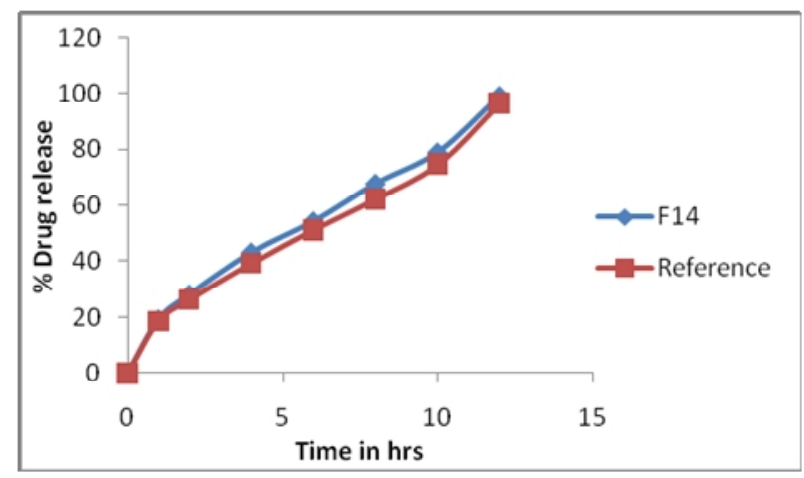

Figure 3: Comparison of In-vitro drug release of Reference and optimized F14

\section{In-vitro drug release study}

Release of the prepared tablets was determined up to $12 \mathrm{~h}$ using USP XX1V (type-II) dissolution rate test apparatus (Electro lab Mumbai, India). $900 \mathrm{ml}$ of $0.1 \mathrm{~N} \mathrm{HCl}$ was used as dissolution medium for first two hours then using 6.8 phosphate buffer for up to $12 \mathrm{~h}$. The rotation of paddle was fixed at $100 \mathrm{rpm}$ and the temperature of $37 \pm 0.5^{\circ} \mathrm{C}$ was maintained throughout the experiment. Samples of $10 \mathrm{ml}$ were withdrawn at $1,2,4,6,8,10,12 \mathrm{~h}$ time intervals and were placed with same volume of fresh dissolution media after each with drawn. The samples were analyzed spectrophotometrically for drug content on UV/Visible spectrophotometer-2400PC Lab India Mumbai at $273 \mathrm{~nm}^{7-9}$.

\section{RESULTS AND DISCUSSION}

Drug Excipient Compatibility Studies reveals that the pure drug and the solid admixture of drug and various ingredients used in the preparation of extended release tablets were characterized by FTIR spectroscopy to know the compatibility. There was no significant difference or the characteristic peak of pure drug was unchanged in spectrum of optimized formulation (F14). Micromeritic properties like angle of repose value of $27.3-33.54^{\circ}$, Carr's index value of 8.95-14.7 and Hausner's ratio 1.09-1.18 indicating flow property excellent to good. Hence powder mixture was found suitable for direct compression method. Post compression parameters like hardness of the tablet were acceptable and uniform from batch to batch variation, which was found to be $5-7 \mathrm{~kg} / \mathrm{cm}^{2}$. All the formulations passed the weight variation test as the \% weight variation was within the pharmacopoeial limits of $\pm 7.5 \%$ of the tablet weight. Friability values were found to be less than $1 \%$ in all the formulations F1 - F24 and considered to be satisfactory ensuring that all the formulations are mechanically stable. The \% drug content for all the formulations were close to 100 and varied between 98.27 to $100.37 \%$ indicating consistency in the manufacturing process. In-vitro drug release study of formulations $\mathrm{F} 4$ and F8 prepared with HPMC K4M and HPMC K15M polymers has successfully extended the model drug release up to $12 \mathrm{~h}$ and they were formulated at $25 \%$ concentration. But Formulation F-14 formulated with Carbopol 971P NF as the polymer has extended the model drug release up to $12 \mathrm{~h}$ at $15 \%$ concentration only. All formulations compared with the marketed product for drug release pattern and were matched using similarity factor $70.11\left(\mathrm{f}_{2}\right)$; which showed that formulation F14 performed similar to the marketed product therapeutically. Based on the evaluation results the formulation F-14 containing Carbopol 971P was selected as best formulation. Different kinetic models were applied to the optimized formulation and observed that F-14 followed first order kinetic model and it was complied with Reference sample. The best linearity was found in Korsmeyer-peppas model (where $\mathrm{n}=0.583$ is the release exponent); Applicability of data indicating Non-Fickian diffusion (or) Anomalous Transport as mechanism of drug release. The stability study for the selected formulation of F-14 was performed as per ICH guidelines. Stability study is carried out for 3 months at $40^{\circ} \mathrm{C} ; 75 \% \mathrm{RH}$, according to $\mathrm{ICH}$ guidelines. The tablets were tested for release during the stability period and confirmed that results were found within the limits.

\section{CONCLUSION}

Drug release of Optimized Formulation F-14 formulated with Carbopol 971P NF as the polymer has extended the Tramadol Hydrochloride release up to $12 \mathrm{~h}$ at $15 \%$ concentration only. 
Excipients used in the formulation reduce the cost, which are available at lower price in market. As the excipients used are mostly available and cheaper at cost. The study includes development of the robust and stable product, which complies with the marketed product.

\section{ACKNOWLEDGEMENT}

The authors are thankful to the Richer Pharmaceuticals, Hyderabad, India and CMR College of Pharmacy, Hyderabad, India for providing necessary facilities to carry out this research project.

\section{REFERENCES}

1. Robinson Lee. Controlled drug delivery; fundamentals and applications. $2^{\text {nd }}$ ed. Marcel Dekkar; New York; 1978. p. 24-26.

2. Robinson R, Lee VH. Influence Of Drug Properties And Route Of Drug Administration On The Design Of Sustained And Controlled Release Drug Delivery System, In Controlled Drug Delivery System, In Controlled Drug Delivery Fundamentals And Applications. $3^{\text {rd }}$ ed; 1995.

3. Chien YW. Oral Drug Delivery And Delivery Systems, In Novel Drug Delivery Systems. $2^{\text {nd }}$ ed., Marcel Dekker, Inc, New York; 1990. p. 139141.

4. Herbert Lieberman, Leon Lachman, Joseph B Schwartz. Phamaceutical dosage forms: Tablets, Vol.1, 2 and 3, second edition.

5. Qiu Y, Zhang G. Research and development aspects of oral controlled release dosage forms. Handbook of Pharmaceutical Controlled Release Technology. Ed. DL Wise, Marcel Dekker Inc., New York, NY, USA; 2000. p. $465-503$
6. Kincl M, Veber M. Characterization of factors affecting the release of low solubility drug from prolonged release tablets. Chem Acta 2004; 502: 107-113. http://dx.doi.org/10.1016/j.aca.2003.09.050

7. Higuchi T. Mechanism of sustained-action medication: theoretical analysis of rate of release solid drugs dispersed in solid matrices. J Pharm. Sci 1963; 52: 1145 -1149. http://dx.doi.org/10.1002/jps.26 00521210 PMid: 14088963

8. Peppas NA, Sahlin JJ. A simple equation for the description of solute release: Coupling of diffusion and relaxation. Int. J. Pharm 1989; 57:169-172. http://dx.doi.org/10.1016/0378-5173(89)90306-2

9. Alfonso R Gennaro. Extended Release and Targeted Drug Delivery Systems, In the Science and Practice of Pharmacy. 21 $1^{\text {st }}$ ed. Lippincott Williamsons and Wilkins Vol -1; 2005. p. 939-94

10. Mr Chaudhary Amol. Formulation Development And Evaluation Of Extended Release Tablets Of Lamotrigine IJPBS 2011; 3(4).

11. Afsar $\mathrm{C}$ Shakh. Formulation and evaluation of sustained release tablets of Aceclofenac using Hydrophillic matrix system. Int J pharm sci 2011; 3: $145-148$.

12. Subramania Nainar Meyyanathan. Formulation and evaluation of sustained release tablets of Aceclofenac using Hydrophillic matrix system. Int J pharm sci 2012; 3: 135-142.

\section{Cite this article as:}

Chilvalvar Sapnil, V. Uma Maheshwara Rao, P. Vishnu, G. Ashok, B. Ajay Kumar. Formulation and evaluation of extended release tablets of Tramadol hydrochloride. Int. Res. J. Pharm. 2013; 4(10):65-69 http://dx.doi.org/ $\underline{10.7897 / 2230-8407.041015}$ 